\title{
Morphological assessments on the origin and supplied territory of the artery for the posterior renal segment
}

Discipline of anatomy, Department I - preclinical disciplines, Faculty of medicine, University "Ovidius" Constanţa

\begin{abstract}
In 105 cases the posterior ramus originated from a renal artery bifurcated into anterior and posterior branches and in 78 cases from trifurcated renal artery. In 12 cases, the posterior ramus originated from a renal artery terminated with four branches. From the aorta, as supernumerary renal artery, the posterior branch originated in 7 cases, 3 cases as double and 4 cases as triple renal arteries. In 86 cases the posterior ramus originated from the anterior branch of the renal artery, superior or inferior or both. The arcade aspect was found in only 134 cases. A particular aspect of the arch is the italic " $\mathrm{S}$ " (or inverted italic "S") or double arch, which we found in 24 cases. This type of posterior branch supplied the entire posterior valve, an aspect found in 11 cases. When the posterior branch was not in arcade, it was arranged transversally and ended by bi or trifurcation. The ending by bifurcation was found in 113 cases and by trifurcation in 17 cases. All of these cases, both the right and the left, supplied the entire posterior valve. In all cases, regardless of any aspect of the posterior branch, it supplied the entire posterior valve in 88 cases. The posterior branch supplied the superior pole in 250 cases, the inferior one in 181 and only the posterior mesorenal part, without participating in the supply of the two poles, in 233 cases.
\end{abstract}

Keywords: artery for posterior renal segment, supplied territory

\section{Iliescu D.M.}

Department of Anatomy, Faculty of medicine, University "Ovidius" Constanţa, Romania

Aleea Universitatii, Nr. 1, Campus B

Constanța, Romania

dan@anatomie.ro

\section{Introduction}

As a voluminous visceral branch of the abdominal aorta, aimed primarily to the kidney, the renal artery has a dual role, nutritional and functional. The renal arteries are the main arteries of blood purification and also the nutritive arteries of the kidneys and their capsule, calyces, pelvis and upper ureters. They also take part in the vascularization of the adrenal gland and lumbar aortic lymph nodes. From the start, a striking disproportion occurs between the relatively small size of the kidney and the considerable arterial trunk. According to the International Anatomical Terminology, the renal artery ends by two branches: the anterior (R. anterior) and the posterior (R. posterior), which is the artery for the posterior segment (A. segmenti posterioris).

According to Testut, the posterior branch, destined to the rear face of the sinus, passes above the pelvis, in contact with its superior border and then down posterior to it. During this traject, the branch gives 3-5 branches which enter the renal parenchyma (the arteries for the posterior face of the kidney). This posterior artery is most often smaller in size than the anterior terminal branch. For Rouvière, the ramus posterior descends to the middle of the hilum, but tangential to its border, so that leaves all free and easily approached the posterior face of the extrahilar pelvis. For Paturet the posterior or retropyelic plan is generally represented by a single artery disposed as an arch on the back of the pelvis and immediately applied to it or to the calyx: it is the retropyelic artery. 
For Callas, the posterior branch leaves the anterior face of the pelvis and passes toward the posterior superior angle of the lobe. It inflects to become vertical along the posterior border of the hilum, thus describing a curve with infero-medial concavity, which leaves open the back of the pelvis. The inferior arteries of second degree (3-5), which starts from artery as „,comb teeth”, immediately penetrate the parenchyma without reaching the bottom of the sinus. Thus, the posterior branch is shortly attached to the hilum and cannot be restrained.

For Cordier, the posterior branch or the posterior apicomezorenal artery or the retropyeIic artery, is 2-3 times smaller than the anterior one and represents the common trunk of the arteries for the posterior face and superior pole. For Guntz, the mesodorsal branch (pyramids $3,4,5$ dorsal) often exceeds the mesorenal territory and participates in dorsal valve supply, totally (18\%), exclusive the base and / or the apical part.

\section{Material and method}

Our study on the artery of the posterior renal segment was performed on a total of 228 human kidney, eviscerated (fresh and formalin preserved) or in situ, within the dissecting anatomy lab. For plastic injection we used organic blocks: kidney with peri-renal fat and the corresponding segments of the abdominal aorta and inferior vena cava. To this statistic are added over 86 aortic angiographies, 88 angioCT movies, 16 MRI and 20 Doppler scans. Not all anatomical landmarks could be studied in all cases, each anatomical landmark being sought on a number of different cases. We assessed the place and the level of origin of the arteries; the arterial branches were observed up to the level of interlobular arteries, studied in relation to the portion of the renal parenchyma they serve. We used the dissection and plastic injection (Tehnovit 7143), and the corrosion with sodium hydroxide, accelerated by heating to 70-900. Ultrasound was performed with a LogiqTM
700, produced by General Electric Medical System. The angiographies were from "Pozimed Diagnostic Center" being performed on a VCT64 Slice GE LightSpeed CT scanner.

\section{Results and discussions}

The origin of the posterior branch was studied on a total of 288 cases, of which 157 (54.51\% of cases) on the right and 131 (45.87\% of cases) on the left.

In 105 cases ( $36.46 \%$ of cases), the posterior branch originated from a bifurcated renal artery into an anterior and a posterior branch, on the right finding 59 arteries (37.58\% of the right renal arteries), and on the left 46 arteries (35.11\% of left renal arteries) (Figure 1).

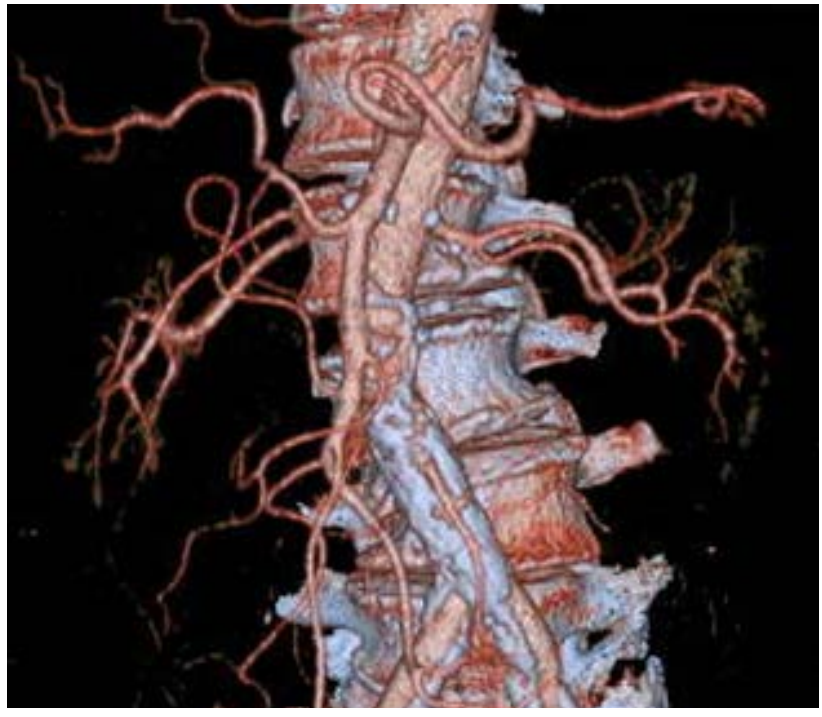

Figure 1 - Both posterior branches from the bifurcation of the renal arteries anterior to the hilum, closer to the aorta

In 78 cases $(27.08 \%$ of cases), the posterior branch originated from a trifurcated renal artery, 43 cases on the right $(27.39 \%$ of right renal arteries) and 35 cases on the left $(26.72 \%$ of the left renal arteries) (Figure 2). 


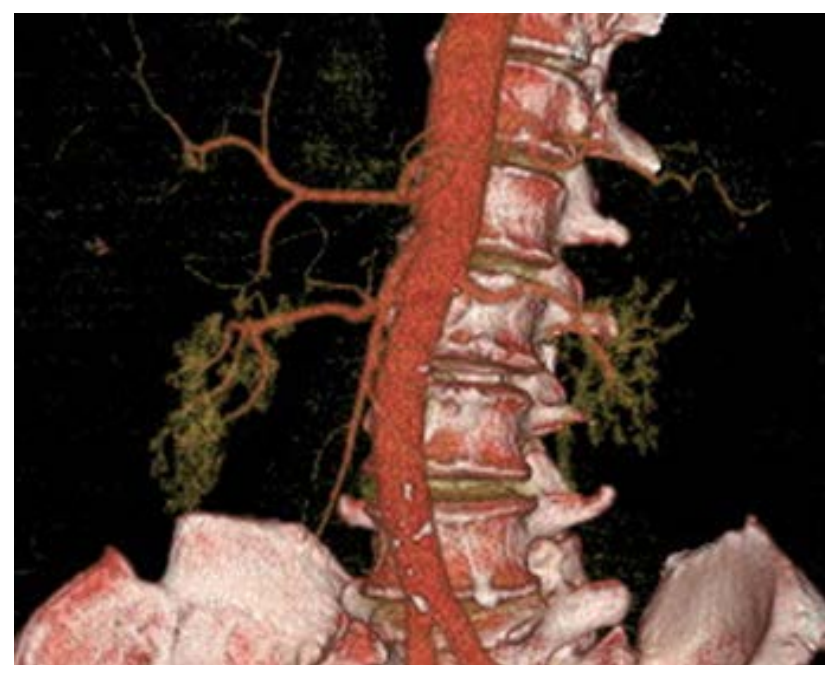

Figure 2 - Right posterior branch originating from a renal artery that ends by trifurcation

In 12 cases $(4.17 \%$ of cases), the posterior branch originated from a renal artery that ended by four branches, 7 cases on the right $(4.46 \%$ of the right renal arteries) and 5 cases on the left (3.82\% of left renal arteries).

From the aorta, as supernumerary renal artery, we found the posterior branch origin in 7 cases $(2.43 \%$ of cases), 3 cases were of double arteries $(1.04 \%$ of cases, 2 on the left and one on the right) and 4 cases were triple renal arteries $(1.39 \%$ of cases, 2 on each side) (Figure 3).

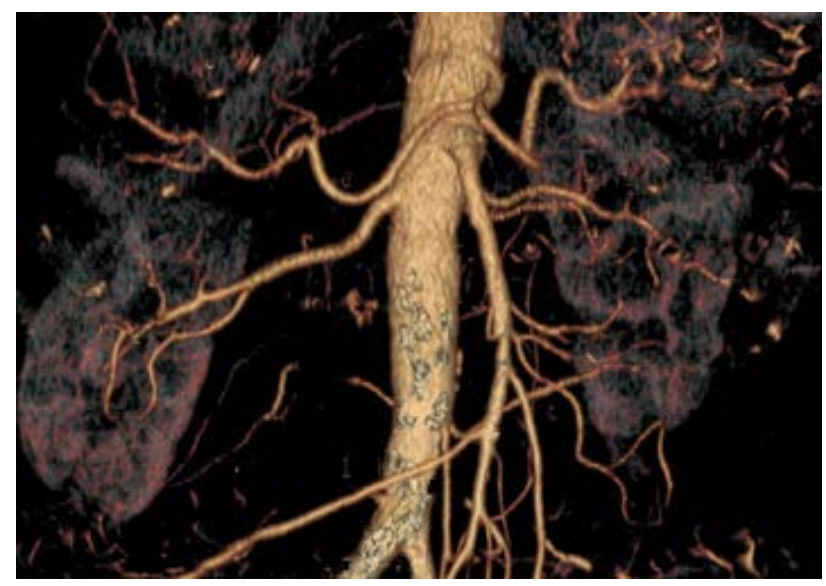

Figure 3 - Left posterior branch originating from the aorta and ending by bifurcation
In 86 cases $(29.86 \%$ of cases) the posterior branch originated from the anterior branch of the renal artery, superior or inferior or even both. In this variation, 45 cases were on the right $(28.66 \%$ of right arteries) and 41 cases on the left $(31.30 \%$ of the left arteries) (Figure 4).

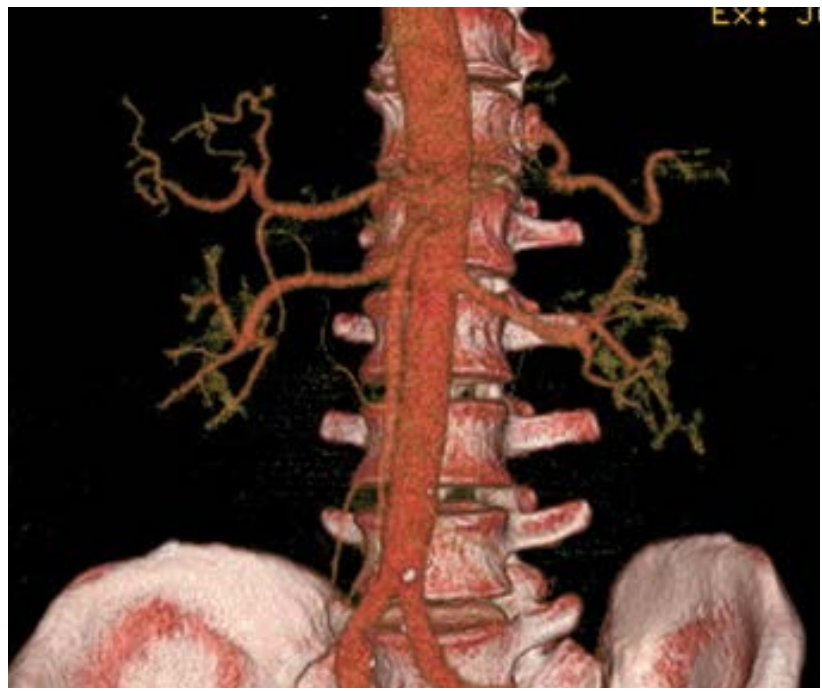

Figure 4 - Left posterior branch originating from the antero-superior branch

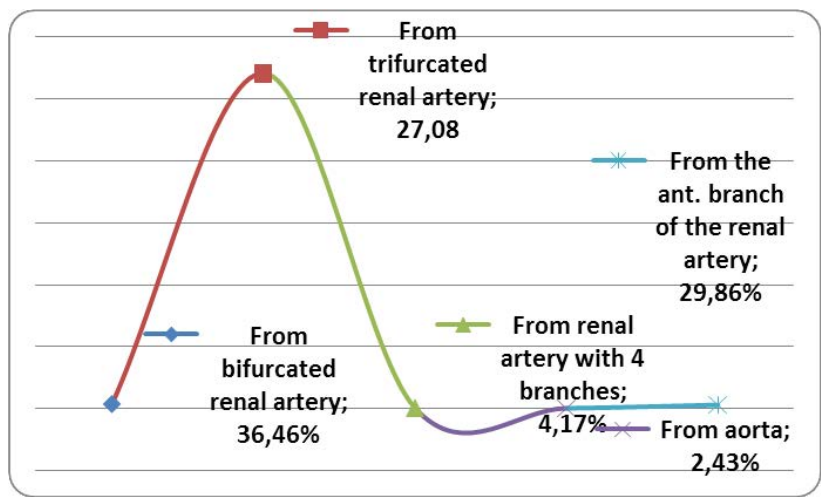

Figure 5 - The origin of the posterior branch of the renal artery

Although the classics describe, in the great majority of cases, the arcade aspect of the artery, we found it in only 134 cases ( $46.53 \%$ of cases), 73 cases being on the right side ( $46.50 \%$ of right arteries) and 61 cases on the left ( $46.56 \%$ of the left arteries) (Figure 6). 


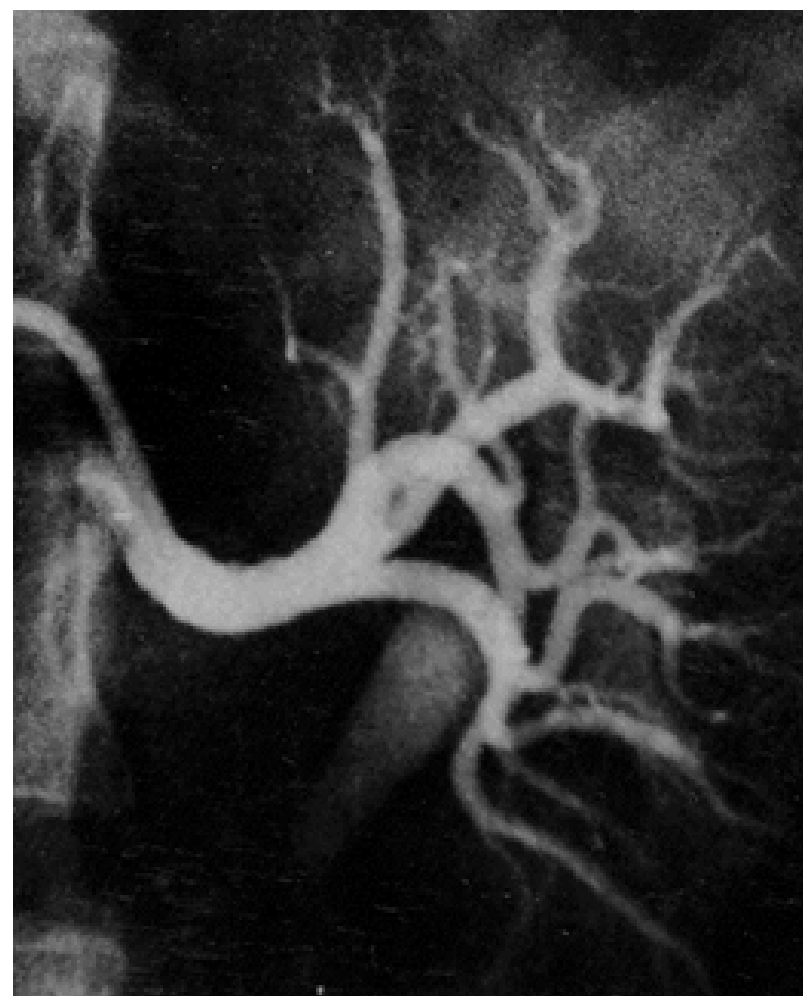

Figure 6 - Posterior branch in arcade

The arcade supplies entirely the posterior valve in 42 cases (31.34\% of the arches), on the right with 24 cases ( $32 \%$ of the right arches), and 18 cases on the left ( $30 \%$ of left arches).

It did not supply the inferior pole in 49 cases (36.572\% of the arcades), 27 cases were on the right (37.5\% of the right arches) and 22 cases on the left (36.67\% of the left arches).

It did not supply the superior pole in 15 cases (11.19\% of the arcades), 8 cases were on the right (10.96\% of the right arches) and 7 cases on the left (11.48\% of the left arches).

The arcade supplied only the posterior mesorenal part in 28 cases $(20.90 \%$ of the arcades), 14 cases on the right side ( $19.18 \%$ of the right arches) and 14 cases on the left ( $22.95 \%$ of the left arches).

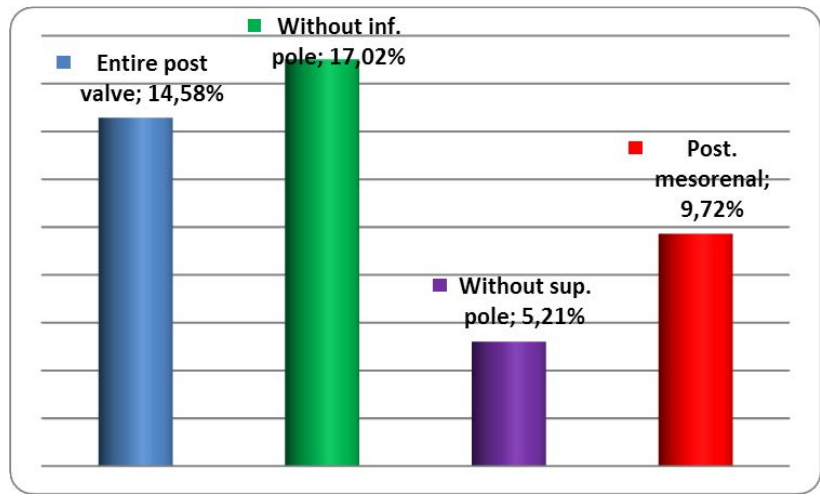

Figure 7 - Territory of supply of the vascular arch

A particular aspect of the arch is the italic "S" or inverted italics "S"(Figures 8 and 9) or double arch, which we found in 24 cases ( $8.33 \%$ of cases), 14 cases on the right ( $8.92 \%$ of right renal arteries) and 10 cases on the left ( $7.63 \%$ of left renal arteries). This type of posterior branch supplied the entire posterior valve in 11 cases $(3.82 \%$ of cases), on the right in 5 cases (3.18\% of the right renal arteries) and on the left in 6 cases $(4.58 \%$ of the left renal arteries).

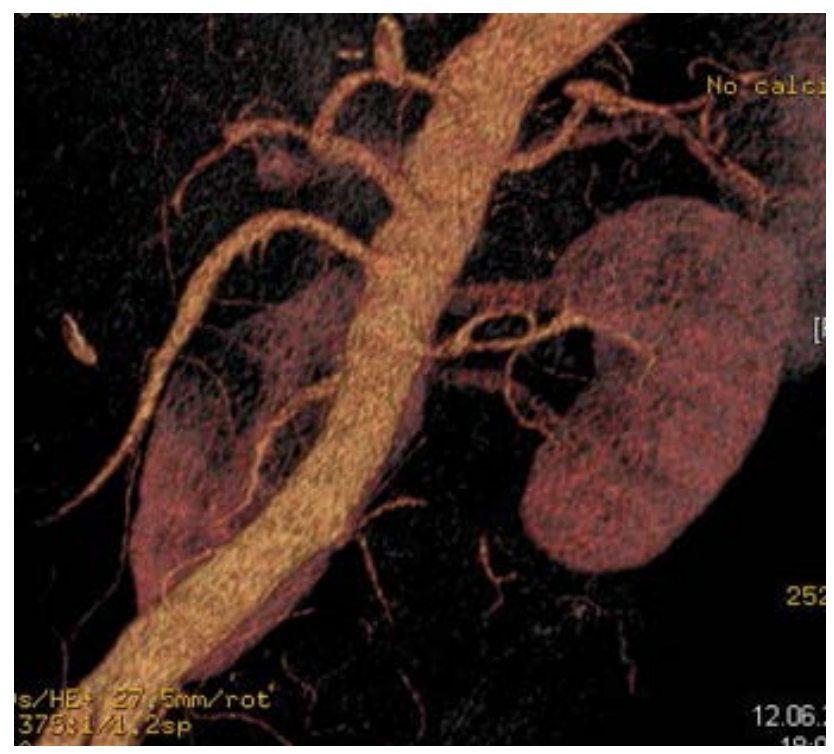

Figure 8 - Left posterior branch in italic " $S$ " 


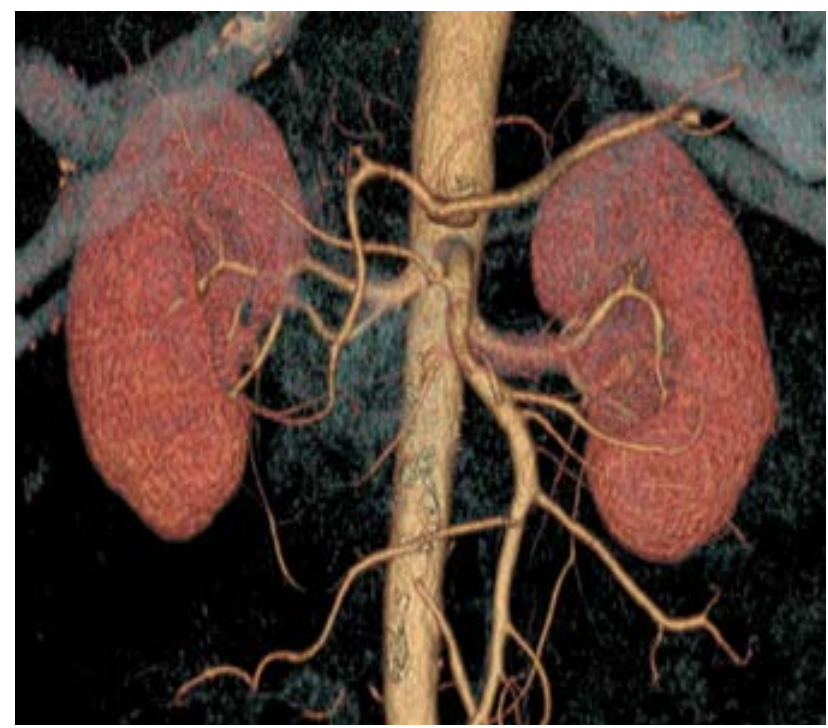

Figure 9 - Right posterior branch in inversed italic " $S$ "

When the posterior branch was not present in arcade, it was transverse, ending by bi or trifurcation.

The ending by bifurcation was found in 113 cases (39.24\% of cases), 59 cases were on the right (37.58\% of right renal arteries) and 54 cases on the left (41.22\% of the left renal arteries).

The ending by trifurcation (Figure 10) was found in 17 cases (5.90\% of cases), 10 cases on the right side $(6.37 \%$ of right renal arteries) and 7 cases on the left (5.34\% of the left renal arteries). All of these cases, both the right and the left, supplied the entire posterior valve.

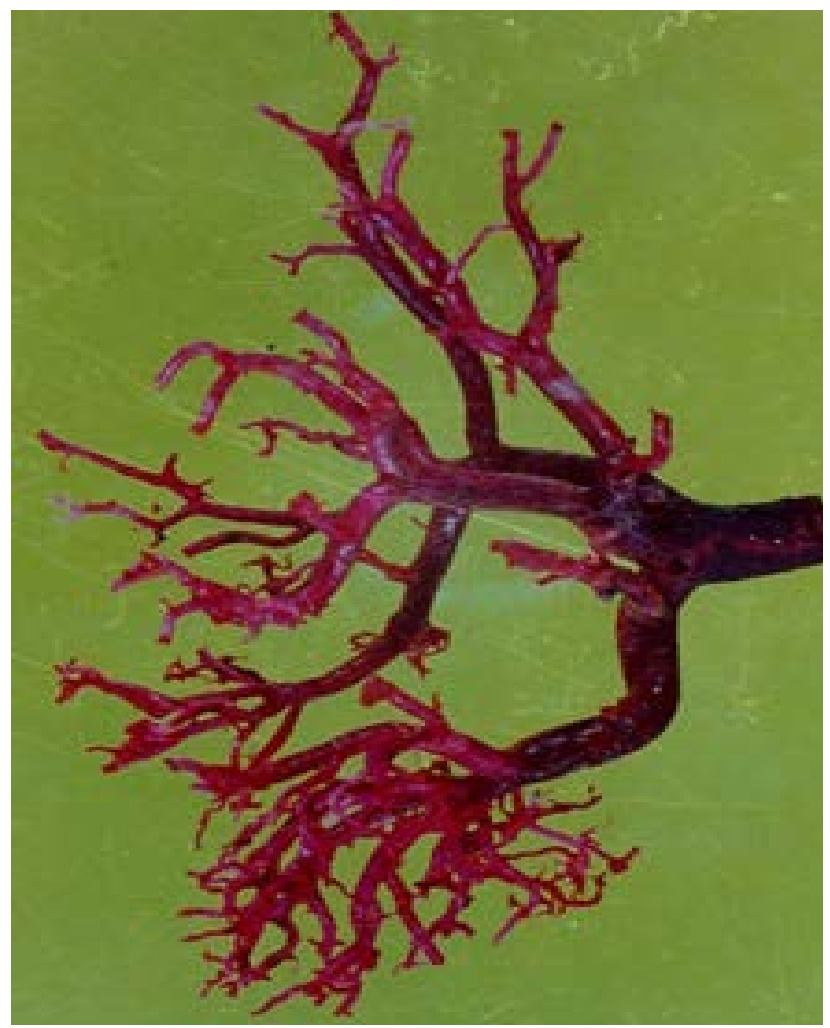

Figure.10 - Posterior branch ending by trifurcation

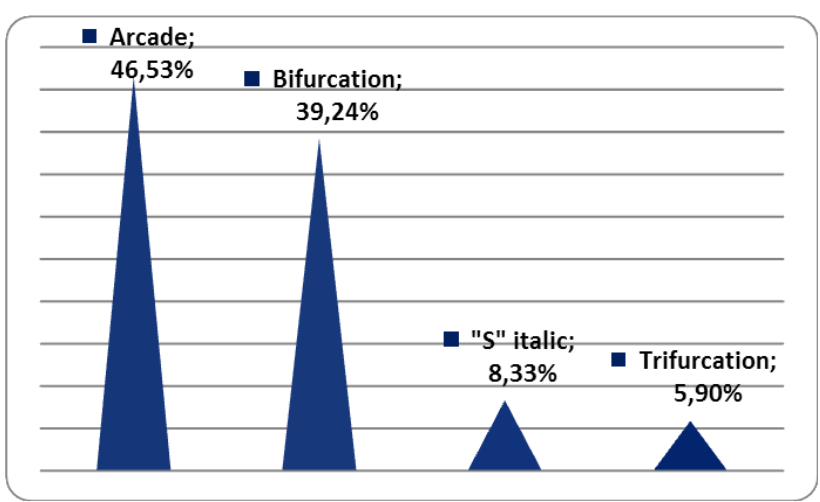

Figure 11- Morphological aspect of the posterior branch of the renal artery

In all studied cases, regardless of any aspect of the posterior branch, it supplied the entire posterior valve of the kidney in 88 cases (30.56\% of cases), in 57 cases on the right side $(36.31 \%$ of right renal arteries) and 31 cases on the left (23.66\% of left renal arteries). 
The posterior branch supplied the superior pole in 250 cases $(86.81 \%$ of cases), the inferior pole in 181 cases $(62.85 \%$ of cases) and only the posterior mesorenal part, without participating in the vasculature of the two poles, in 233 cases $(80.90 \%$ of cases) (Figures 12 and 13).

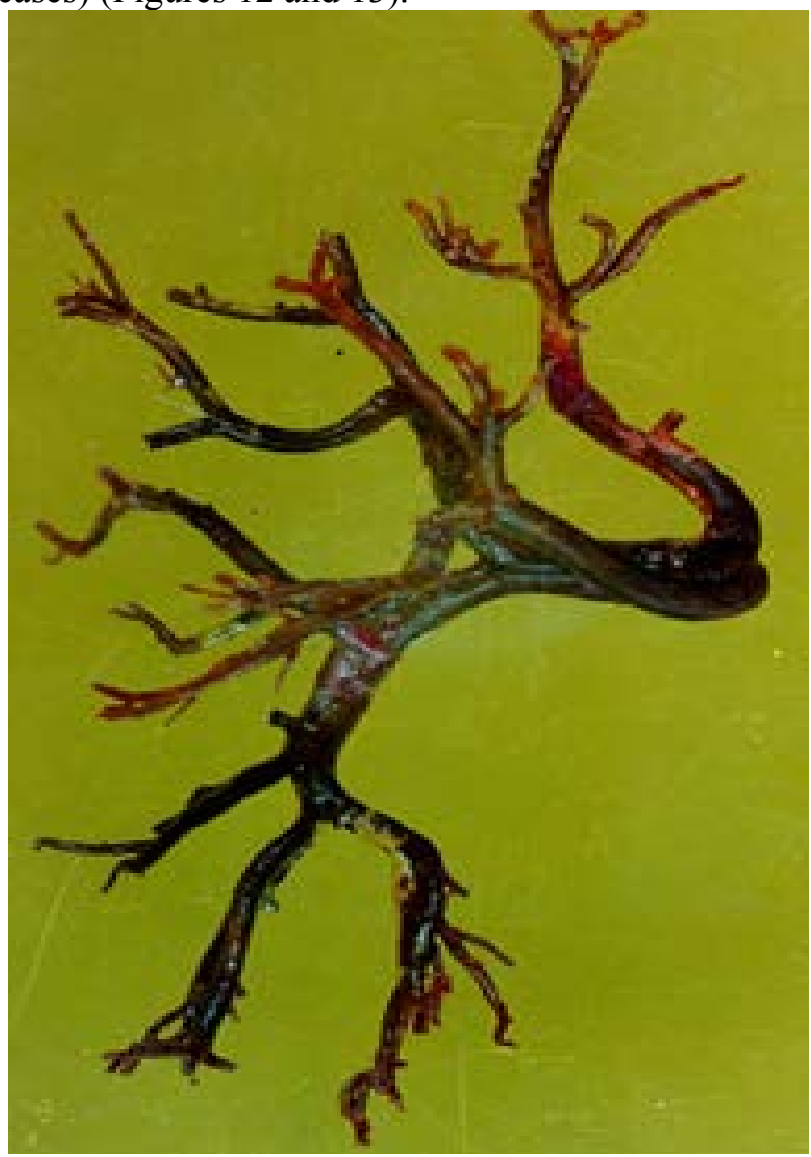

Figure 12 - Posterior branch that supply only the posterior mesorenal part

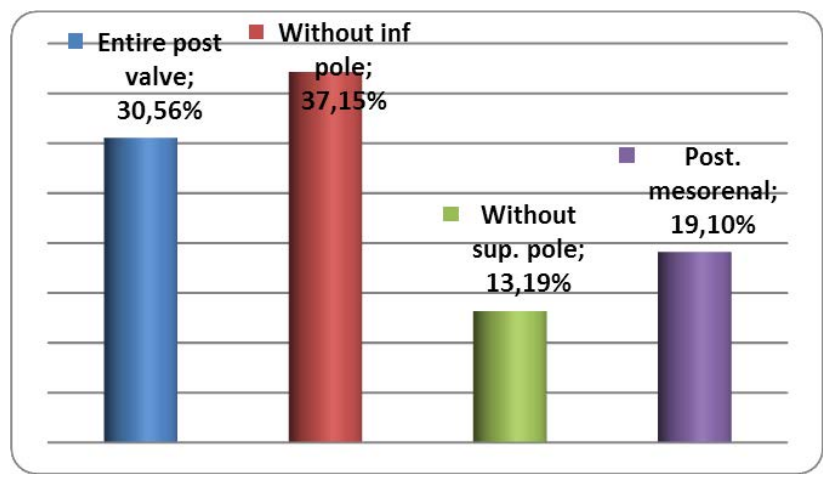

Figure 13 - Territory of supply of the posterior renal branch.

Compared to the literature that shows the posterior branch origin rather contradictory, the results are vastly different from ours; the posterior branch originating from a renal artery bifurcated in anterior and posterior was found in only $38.4 \%$ of cases [close to Wiart, cited by 16, 17], smaller than [1] with $75 \%$, [2] with $77 \%$ and Schmerber quoted by [8.9] with $61.33 \%$. Also in the case of the origin of the posterior branch from a trifurcated renal artery, we found the percentage of $27.08 \%$ as very small compared to the percentage of Wiart (66\%), but close to the percentage of [1] with $25 \%$, greater than the percentage of [2]. The origin of a renal artery ended with four branches we encountered a very similar percentage of [2] (with a difference of only 0.79 percent), but the origin from the anterior branch of the renal artery $(29.86 \%)$ was found it to a much higher percentage than in [2] 9.84\%. Augier [cited by 8 and 9] and Schmerber [cited by 8 and 9] describe it from the renal artery bifurcation in superior and

Table I - Aspect and ending manner of the posterior branch

\begin{tabular}{|l|c|c|c|c|c|}
\hline \multicolumn{1}{|c|}{ UTHOR } & ARCADE & BIFURCATED & TRIFURCATED & ITALIC "S" & NETWORK \\
\hline Arvis & + & - & - & ++ & - \\
\hline Callas & + & - & - & - & - \\
\hline Cordier & $70 \%$ & $25 \%$ & -+ & -+ & - \\
\hline Ecoiffier & ++ & + & + & - & - \\
\hline Paturet & + & - & - & - & - \\
\hline Rouviere & - & - & - & - & + \\
\hline Pers. cases & 134 & 113 & 17 & 24 & + \\
& $(46,53 \%)$ & $(39,24 \%)$ & $(5,90 \%)$ & $(8,33 \%)$ & \\
\hline
\end{tabular}


inferior branches. The origin from a bifurcated the renal artery in anterior and posterior is cited by Brodel with $25 \%$ [quoted by 2], [3] with $40 \%$, [4 and 5] with $50 \%$, [ 6 and Zondeck quoted by 16 and 17$]$ with $75 \%$, $[7,8,9,10$ and Torlois cited by 8$]$. The origin from a trifurcated renal artery $[4,6$, Zondeck] was found in $40 \%$ of cases, [5] in $50 \%$ of cases, while $[8,9,10$, Torlois and Brodel] in $60 \%$ of cases. Other authors $[11,12,13,14,15]$ described its origin only from one renal artery terminated by trifurcation.

Regarding the arcade aspect of the posterior branch, [16 and 17] finds the percentage higher than ours by $23.47 \%$, and the bifurcation ending in a lower percentage with $14.24 \%$. [4] mentions the italic "S" (more frequently) and arcade, [1 and 3] mentions only the appearance in arcade, [6] found that half of the cases the posterior branch shows an arcade and in the other half of the cases being terminated by bi and trifurcation. Only [14] mentions the appearance of posterior rami arranged as a network.

The vascular territory of the posterior ramus rarely includes the entire posterior valve, according to [15] in $18 \%$ of cases, which is a smaller percentage of $56 \%$ than ours. The cases of no blood supply for the lower pole were found by [15] with $19.85 \%$ more frequently than us, while the upper pole no blood supply was only $2.81 \%$ higher and the supply of only posterior middle part was less with $10.10 \%$. $[1,6,16,17]$ showed that the posterior ramus supply mostly the whole posterior valve (in two thirds of cases), $[1,16,17]$ finding that in one third of the cases does not supply the superior pole and [6] that in one third of the cases does not supply the inferior pole.

\section{Conclusions}

When addressing the issue of renal vascular anatomy, it is noted the extreme discordance between the authors, imposed not only by the high variability of the kidney situation but mostly by the great variability of the anatomy of renal vessels and renal arteries in particular as regards their origin, traject and collateral branches and their termination.

As in other parts of the body, at the renal level, the needs of modern surgery are those that determine and direct the anatomical research. Indeed, the systemic study of the renal vessels known unmatched momentum with partial nephrectomy; the present studies, although they manage to clarify some knowledge on this subject, leaves the need for further discussion, clarification and details. Given its major role in the functioning of the entire body, the today surgical therapy in renal pathology aims towards the organ preservation, either fully or only partially, and only when it fails it may pass the final act, the renal transplantation. The difficulties encountered, in particular the reduced opportunities to find a donor, impose to continue to give importance to the segmental surgery of the kidney and to the finding of new operative techniques.

The posterior terminal branch, regardless of its appearance, supplies the whole posterior valve in about $1 / 3$ of the cases. Taking into account that the anterior branch does not extend its posterior territory in $1 / 5$ of cases, that the superior polar does not supply the posterior valve of the superior pole in $1 / 3$ of cases

Table II - Territory of supply of the posterior branch

\begin{tabular}{|l|c|c|c|c|}
\hline \multicolumn{1}{|c|}{ AUTHOR } & DORSAL VALVE & WITHOUT INF POLE & $\begin{array}{c}\text { WITHOUT SUP. } \\
\text { POLE }\end{array}$ & $\begin{array}{c}\text { WITHOUT } \\
\text { POLES }\end{array}$ \\
\hline Callas & ++ & - & + & - \\
\hline Cordier & ++ & - & -+ & - \\
\hline Ecoiffier & ++ & + & - & - \\
\hline Guntz & $18 \%$ & $57 \%$ & $16 \%$ & $9 \%$ \\
\hline Pers. cases & 88 & 107 & 38 & 55 \\
& $(30,56 \%)$ & $(37,15 \%)$ & $(13,19 \%)$ & $(19,10 \%)$ \\
\hline
\end{tabular}


and the inferior polar does not exceed the anterior valve of the inferior pole in $1 / 4$ of cases, it results that, in these cases, there is virtually no unnamed line of Hyrtl, either partially or totally. This was supported by [1], which without giving percentages, showed that there is a balance between the anterior and the posterior vascular systems, the boundaries between the anterior and posterior vascular territories being very irregular in the middle of the kidney and variable towards the upper pole. Therefore, in these cases, the less hemorrhagic region will be towards the external convex border than the posterior face, as shown by Hyrtl. [18] finds that in 13 cases out of 61 (21.31\%) the separation line between the anterior and the posterior territories is aimed towards the external border of the kidney, thus could not confirm the existence of the avascular line of Hyrtl.

The discrepancies between the statistics of different authors led us to assume that there are morphological differences between the renal arteries linked to geographical areas they belong. In the same geographical areas, the differences reported may be the result of some predisposing factors that may influence the distribution of pressure in a given period of time. In support of these assumptions comes the finding that the higher number of supplementary renal arteries we found were in kidneys from subjects closely aged.

\section{References}

1. Calas F., Martin R. \& Convert A. (1963). Contribution a l'étude de la vascularization du rein. C.R. Assoc. Anat. 117, 408-421

2. Ferreira A. Dos Santos, Pereira J., Pires. M. \& Andrea M. (1967). Segmentation artérielle du rein. C.R. Assoc. Anat. 138, 526-533

3. Paturet G. (1958). Tome III, Fascicule I, Appareil circulatoire. In Masson (Eds.), Traité d'anatomie Humaine (pp. 511-526)

4. Arvis G. (1968). Anatomie practique du sinus du rein. Bull. Asoc.Anat., 53 Congres, Tours. 432-444
5. Papin E. (1928). Chirurgie du rein. Tome premier, Paris: Ed. Gaston Doin

6. Ecoiffier J. (1972). L'artériographie renale. Annales de radiologie

7. Gregoire R. (1920). L'appareille uro-génitaI. Paris: Ed. Masson

8. Testut L., Latarjet A. (1931). Traité d'anatomie humaine. Tome cinquième (pp. 30-39)

9. Testut L., Latarjet A. (1949). Peritoine. Appareil uro-génital. In Traité d'anatomie humaine. Tome cinquième (pp. 99-151). Paris

10. Ternon Y. (1959). Anatomie chirurgicale de l'artère rénale. Bases d'un segmentation arterielle du rein. J. Chir., 78, 517-521

11. Poirier P. (1896). Traité d'anatomie humaine. Tome deuxième (pp. 775-777). Paris

12. Gerard G. (1921). Manuel d'anatomie humaine (pp. 293-294, 1076-1095). Paris

13. Williams P., Warwick D., \& Bannister. L. (1995). Gray's Anatomy - 38th ed. (pp. 1826-1827). London: Churchill Livingstone

14. Rouviere H. (1978). Anatomie humaine descriptive, topographique et functionelle. Tome II. Tronc. Paris: Masson et Cie (pp. 519-535)

15. Guntz M. (1967). Radio-anatomie de l'artère rénale. Deductions chirurgicales. C.R. Assoc. Anat. 148, 623- 631

16. Cordier G.J. (1939). Anatomie. Rein. Encyclopédie médico-chirurgicale (pp. 1-8)

17. Cordier G., Nguyen-Huu \& Bui-Mon-Hung (1964). Segmentation arterielle du rein. Presse Med. 72(42), 2433-2438

18. Ferreira A Dos Santos, Pereira J.P. \& Andrea M. (1967). Segmentacao arterial do rin (61 casos). $J$. Soc. Cien. Med. Lisboa. 5, 394-416

19. $* * * * * * * * * * *$ (1998). Terminologia Anatomica. International Anatomical Terminology. Ed. Thieme, pp. 88 